\title{
6 Los factores verbales: modelo explicativo
}

\subsection{Introducción}

En los capítulos 4 y 5 se ha alcanzado la conclusión de que, mientras la telicidad no parece desempeñar un papel relevante en la explicación del MDO en español, la afectación sí lo desempeña. Esta conclusión se ha obtenido tras el estudio de estos dos factores desde dos perspectivas diferentes (sincrónica y diacrónica) y mediante dos metodologías distintas (estudio de cuestionarios y estudio de corpus) que, de manera coherente, han arrojado un mismo resultado: la afectación del objeto implicada por el verbo ha influido de manera significativa en el MDO. Esta influencia se puede apreciar en el ámbito de los objetos directos humanos indefinidos y se ha mantenido desde el comienzo del desarrollo del fenómeno hasta la actualidad.

Determinado el impacto de este factor tanto a nivel sincrónico como diacrónico, la única pregunta que queda por responder de las que se plantearon en la introducción es la siguiente: ¿cómo se explica, desde un punto de vista lingüístico, que la afectación contribuya al uso del MDO junto a otros factores como la animacidad o la definitud? El objetivo de las siguientes páginas es el de ofrecer una respuesta a esta pregunta, que explique al mismo tiempo el porqué de la influencia de la afectación y del resto de factores que se mencionaban en los capítulos 2 y 3.

El capítulo está dividido en dos partes: (i) la primera está relacionada con el origen del MDO y con los factores que provocaron la aparición de la marca y su difusión en las primeras etapas de su desarrollo; (ii) la segunda parte aborda el fenómeno desde una perspectiva sincrónica, y en ella se propone un modelo de interacción de los distintos factores para explicar el marcado. Dicho modelo está basado en el concepto de prominencia semántica y, por ello, a lo largo del apartado 6.3 se desarrolla cuál es la utilización que se hace de dicha noción antes de explicar de qué manera contribuye a la explicación de los resultados obtenidos en la parte experimental de esta investigación.

Por último, en el apartado 6.4 se recogen todas aquellas ideas fundamentales y conclusiones alcanzadas a lo largo del capítulo.

\subsection{Relevancia de la oposición acusativo-dativo}

Para responder a la última de las preguntas planteadas en esta investigación, en este apartado se ha determinado buscar la respuesta desde dos perspectivas diferentes: la primera pone el punto de mira en el origen mismo del MDO y la 
segunda, en la situación actual del fenómeno. La revisión detallada del origen contribuye a explicar por qué la interacción de determinados factores desembocó en la aparición del marcado preposicional; por otro lado, el análisis sincrónico permite comprender por qué los factores que provocaron la aparición del MDO han continuado determinándolo hasta alcanzar el estado de desarrollo que este presenta actualmente.

El capítulo 3 señalaba que la mayoría de los estudios acerca del fenómeno coindicen en defender que el origen del marcado preposicional se debió a una confusión entre los casos latinos acusativo y dativo, cuando estos aparecían bajo unas condiciones determinadas. Este trabajo sostiene la idea de que dicha confusión, más allá de una coincidencia formal de ambos casos en una determinada posición, se debió a la cercanía semántica de los casos acusativo y dativo y que, precisamente, este fue el hecho desencadenante del MDO y mediante el que se puede explicar el porqué de los factores implicados en el fenómeno.

\subsubsection{Origen del MDO: confusión histórica entre dos casos}

Para entender el origen del MDO, como ya se ha señalado en el capítulo 3, es necesario remontarse a un cambio previo que se produjo en latín y que consistió en el cambio de codificación del objeto indirecto. El tercer argumento de los verbos transitivos en latín pasó de codificarse mediante el caso dativo a hacerlo mediante el giro preposicional ad + acusativo. Company Company $(2014,1234)$ señala que «el origen del cambio está ya al menos desde el latín clásico y que se manifiesta en varios hechos relacionados con las propiedades funcionales y distribucionales del caso dativo, propiedades que, por un lado, reflejan estrechas afinidades entre este caso y el acusativo, paciente o tema, y que, por otro, permiten al dativo alternar con otros casos precedidos de preposición para expresar valores semánticos afines a los del propio dativo».

En primer lugar, el dativo aparecía marcando el segundo argumento de los verbos de algunas clases léxicas que implicaban un cierto grado de afectación, como nocere 'perjudicar', placere ‘agradar' o insidiari 'atentar, acechar'. En (112) se muestran dos ejemplos de este uso del dativo con los verbos nocere e insidiari, respectivamente.

(112) Verbos del latín con objeto dativo (Baños 2009, 193)

a. ut cum illis nocere se speret, rei publicae noceat (Caes. civ. 1,8,3) 'no sea que, al intentar perjudicarles, perjudique a la república'

b. Desinant insidiari domi suae consuli

(Cic. Cat. 1,32) 'dejen ya de atentar contra el cónsul en su propia casa' 
En un análisis llevado a cabo en Pinkster (1995, 68-70) de la forma que toma el segundo argumento de los verbos en el De oratore, de Cicerón, se llega a la conclusión de que, si bien el acusativo es la forma prototípica para codificar estos argumentos, el dativo alcanza casi una cuarta parte del total de casos. Sin embargo, con el paso del tiempo algunos de los verbos que marcaban su argumento interno con dativo experimentaron un proceso de «transitivización» y comenzaron a marcarlo con acusativo. Este proceso lo que evidencia es la cercanía semántica que presentaban ambos casos y puede observarse con ejemplos como el de curare, verbo que prototípicamente había marcado su argumento interno con dativo, pero que ya en época de Plauto se utilizaba mayoritariamente acompañado de acusativo, como muestra el ejemplo de (113a); no obstante, en ocasiones continuó pareciendo con dativo, tal como se aprecia en (113b). Según Álvarez Huerta, no es posible constatar diferencia semántica apreciable entre uno y otro caso, pues en ambos el objeto, humano, experimenta previsiblemente el mismo grado de afectación.

(113) Transitivización de verbos que regían dativo (Álvarez Huerta 2009, 134)
a. Curato aegrotos domi
(Plaut. Capt. 190)
'Cuida a los enfermos en casa'
b. Lampadio, obsecro, cura (Plaut. Cist. 594)
'Cuida de Lampadio, te lo ruego'

En segundo lugar, la función prototípica del dativo era la de codificar el tercer argumento de los verbos; a pesar de ello, en latín existían también las llamadas construcciones de doble acusativo con verbos como docere 'enseñar', en las que ambos argumentos, como se aprecia en (114), se codificaban en acusativo, por lo que acusativo y dativo compartían una vez más fronteras gramaticales.
(114) Construcciones con doble acusativo (Company Company 2014, 1234) Doceo grammaticam pueros.
'Enseño gramática a los niños.'

Un tercer hecho que acercaba ambos casos consistía en que determinados verbos que regían dativo permitían la pasivización de su argumento, que pasaba a desempeñar la función de sujeto paciente, función que estaba asociada generalmente a los argumentos que originariamente presentaban acusativo. Los ejemplos de (115) muestran este hecho, donde (115a) recoge un ejemplo de pasivización de un argumento en acusativo, mientras que (115b) representa esos casos en los que se permitía la pasivización de argumentos dativos. 
(115) Pasivización de acusativos y dativos (Company Company 2014, 1235)

a. doceo grammaticam pueros $>$ pueri grammaticam ad me docentur ‘enseño gramática a los niños' > 'los niños son enseñados por mí (en) gramática'

b. invident fratri $>$ frater invidentur

'envidian al hermano' > 'el hermano es envidiado'

Por último, el dativo alternaba en bastantes construcciones tanto con otros casos, como el acusativo o el genitivo, como con algunos giros preposicionales, tales como ad + acusativo o pro + ablativo. Dichas alternancias evidencian la debilidad del caso dativo en el conjunto del sistema casual latino (Baños 2009, 186) y ayudan a entender la temprana aparición de $a d$ + acusativo para codificar el objeto indirecto. Este giro se documenta ya desde los inicios del latín clásico. Las primeras documentaciones de objetos indirectos codificados mediante $a d+$ acusativo son con pronombres personales y se registran, en un principio, junto a usos del dativo simple, como muestran los ejemplos de (116).

(116) Variación entre dativo y ad + acusativo para codificar el objeto indirecto (Baños 2009, 189)

a. has ego tibi litteras eo maiore misi interuallo (Cic. fam. 8,4,3) 'te envié esta carta con más retraso. ..'

b. itaque ad te litteras statim misi (Cic. fam. 5,4,1) 'así que te envíe de inmediato la carta'

Este tipo de contextos habría facilitado desde época temprana en el latín clásico la sustitución de un «caso débil», como el dativo, por el giro preposicional. No obstante, apunta Baños, un análisis en profundidad de este tipo de ejemplos muestra que, al menos en latín clásico y arcaico, dativo y ad + acusativo denotan funciones semánticas distintas: mientras que el dativo personal marca el Receptor/Destinatario de la acción verbal, el giro preposicional expresa dirección espacial, como término de un movimiento. Por esta razón, las supuestas alternancias se dan siempre en esta época con verbos como mittere 'enviar', scribere 'escribir' o deferre 'empujar'; o con predicados como dare litteras 'entregar/enviar una carta', que implican un desplazamiento espacial, como en (116b).

Company Company (2003; 2014) sostiene que esta situación de convivencia de los dos significados acabó evolucionando y desembocando en la desaparición del dativo. Finalmente, el giro preposicional sería el que ocuparía ambos espacios semánticos por medio de un proceso de extensión analógica del significado locativo que poseía la preposición ad. Dicho proceso implicó que el sentido etimológico de la preposición, de 'dirección hacia una meta', se extendiese para marcar 
una entidad que, de alguna manera, también resultaba alcanzada por la acción del verbo, es decir, el objeto indirecto. Esta extensión, según la autora, podría considerarse un cambio metonímico de la parte por el todo o del contenido por el continente. La expresión ad + acusativo se empleaba muy frecuentemente con localizaciones que incluían en su significado componentes humanos, como ad villam 'al pueblo', ad castram 'a los campamentos' o ad urbem 'a la ciudad', de modo que las partes contenidas pasaron a ser codificadas de la misma manera que el conjunto del continente. Así, el valor de 'dirección hacia' se habría extendido para marcar a los seres humanos, contenidos en la localización, que resultan alcanzados por la acción del verbo (2014, 1237).

En este punto, la marcación prepositiva de los objetos indirectos con ad se extendió de forma análoga a los objetos directos humanos con un elevado grado de individuación. Como se explicó en el capítulo 3, la extensión afectó en primer lugar a aquellos objetos en posición topicalizada, para posteriormente pasar a marcar también aquellos en posición normal. La condición de humanidad del referente y el carácter individuado eran rasgos que los primeros objetos directos marcados compartían con los objetos indirectos, por lo que la diferencia entre un tipo y otro de objeto residía tan solo en el tipo de meta que cada uno codificaba. Mientras que el objeto directo codificaba la meta inmediata de la transitividad, el objeto indirecto codificaba la meta última.

La propuesta que se desarrolla a lo largo de las siguientes páginas parte, precisamente, de esta perspectiva del origen del MDO. La noción de afectación se revela como fundamental en la aparición del fenómeno, debido a su contribución a la expansión de la preposición ad del dativo al acusativo. Esta idea se basa en una noción de transitividad más amplia de lo que propone el concepto tradicional y en una concepción de la afectación como la condición que adquieren los participantes del evento hacia los cuales se dirige la acción expresada por el verbo. Con la finalidad de profundizar en esta idea, el siguiente apartado se adentra en el concepto de afectación partiendo de la relación entre acusativo y dativo, y de las características que definen ambos casos.

\subsubsection{Proximidad semántica del acusativo y del dativo}

\subsubsection{Estudios clásicos}

La defensa de la estrecha relación que existe entre los casos acusativo y dativo no es una propuesta reciente, sino que constituye una idea que viene siendo elaborada ya desde hace tiempo. Meyer-Lübke (1899) es uno de los primeros autores que apunta en esta dirección al señalar que la distinción entre acusativo y dativo del latín carece ya de sentido, si se atiende a la evolución de las lenguas roman- 
ces. En su lugar, propone diferenciar entre objeto pasivo (Passivobjekt) y objeto directivo o de dirección (Direktivobjekt); sin embargo, señala algunos contextos en los que ambos tipos de objeto se acercan tanto que algunos verbos muestran variación a la hora de codificar su argumento interno. Estos contextos a los que Meyer-Lübke hace referencia son precisamente aquellos en los que el referente del objeto es humano, como puede apreciarse en (117).

(117) Variación en la codificación del argumento interno (Meyer-Lübke 1899, 391)

a. croire les médecins

creer los médicos

'creer a los médicos'

b. croire aux médecins

creer DAT.los médicos

'creer a los médicos'

Asimismo, Pottier (1957, 550-551) defiende que, de los cuatro «casos cinemáticos» del latín, dos de ellos implican el alejamiento de un límite (nominativo y ablativo) y los otros dos el acercamiento a este (acusativo y dativo). Lo que diferenciaría, según el autor, a cada uno de los casos entre sí sería el punto de vista. Para el ablativo, el desplazamiento desde el límite se considera en su término, mientras que, para el nominativo, el movimiento es visto desde el punto de su comienzo; $y$, respecto a la diferencia entre acusativo y dativo, la diferencia sería exactamente la misma, atendiendo al final y al comienzo del movimiento, respectivamente. En definitiva, de nuevo nos encontramos ante una defensa de la proximidad semántica entre acusativo y dativo.

Cano Aguilar (1981, 325), por su parte, caracteriza semánticamente el objeto indirecto como la entidad destinataria de la acción, que puede recibir «daño» o «beneficio». Esto le lleva a señalar la proximidad semántica que se produce entre la definición mencionada y los objetos directos de verbos como los de matar a alguien o ayudar a alguien. Dicha proximidad se produce cuando los objetos directos son animados y pueden considerarse como afectados. Ante esta situación, defiende la concepción fillmoriana de la existencia de dos casos: el Objetivo y el Dativo, el primero para los argumentos inanimados y el segundo para los animados. Así, defiende el autor, todos los argumentos animados procederán del caso Dativo, aunque en algunos casos se manifiesten como objetos directos y en otros como indirectos. Cano Aguilar menciona algunos ejemplos de Schroten para defender esta hipótesis y se apoya en que la función semántica es la misma en los objetos directos de (118a), que en sus respectivos objetos indirectos en (118b). 
(118) Proximidad semántica entre dativo y acusativo (Cano Aguilar 1981, 325)

a. ayudar a alguien

a'. asustar a alguien

b. dar ayuda a alguien

b'. dar un susto a alguien

Además, este autor apunta ya la idea de que la igualdad formal que ambos casos manifiestan reforzaría de alguna manera su proximidad semántica, hecho que es precisamente el que pretende investigar este capítulo.

Y, en lo que se refiere a textos clásicos que han apoyado esta idea, hay que destacar también el trabajo de Dietrich (1987). Este autor considera que el carácter personal de los objetos directos humanos y de los objetos indirectos los sitúa en posiciones semánticamente muy próximas y, por ello, se refiere a ellos como objetos compañeros (Partnerobjekte). La denominación se justifica porque ambos tipos de objetos no solo se caracterizan por sufrir o soportar las consecuencias derivadas de la acción verbal, sino que además mantienen cierto tipo de relación de interacción con el sujeto (1987, 73-74).

Como se ha podido comprobar, los textos (ya clásicos) que han defendido la proximidad semántica entre determinados acusativos y los dativos han sido bastante numerosos. En los últimos años han surgido investigaciones en este sentido que plantean la dificultad para establecer la línea divisoria entre ambos casos (Delbecque/Lamiroy 1996) o incluso predicen la desaparición de uno de ellos debido al progresivo sincretismo morfológico existente entre ellos (Company Company 2002a).

\subsubsection{La dificultad para distinguir acusativo y dativo en español: Delbecque/Lamiroy (1996)}

Delbecque/Lamiroy (1996) llevan a cabo un estudio cuyo objetivo fundamental es el de definir el caso dativo en español. Las autoras comienzan su trabajo señalando la dificultad para acotar su objeto de estudio, debida fundamentalmente al doble sincretismo formal que presentan en muchas ocasiones los casos dativo y acusativo en español. Este doble sincretismo es el que se produce, por un lado, entre el dativo y el acusativo con MDO en los SN léxicos; y, por otro lado, el que se da entre los clíticos de uno y otro caso, debido fundamentalmente al impacto del leísmo.

Analizados los dos fenómenos que provocan este doble sincretismo, las autoras llegan a la conclusión de que, aunque la oposición acusativo/dativo, heredada del latín, se ha mantenido en español, la distinción entre ambos casos se vuelve muy difícil basándose solo en criterios morfosintácticos y, por ello, 
suponen que debe haber implicados otros criterios semántico-cognitivos que expliquen la diferencia. El sincretismo de caso hace suponer que lo que puede estar ocurriendo en español es uno de los siguientes procesos: bien una desaparición de la distinción casual, o bien una remodelación de las relaciones gramaticales en lo que a rasgos semánticos se refiere, en el sentido de que se estén asociando al dativo contextos que antes pertenecían al acusativo. Sea como fuere, el principio que parece regir el uso del acusativo y del dativo en la actualidad puede resumirse de la siguiente manera: los participantes distintos del sujeto pueden presentarse como un mero paciente del proceso por medio del acusativo o puede atribuírseles una posición más prominente dentro del evento por medio del dativo (entendiéndose en este caso una equivalencia entre acusativo con MDO y dativo, debido al sincretismo morfológico de marcado de caso). El uso del dativo, por lo tanto, queda sujeto a una serie de factores que son los que otorgan prominencia a un argumento. Entre dichos factores se pueden destacar los rasgos del SN, el tipo de verbo e, incluso, las preferencias del propio hablante (Delbecque/Lamiroy 1996, 109).

Delbecque/Lamiroy señalan que, cuando el dativo ocupa una posición actancial, puede aparecer en tres tipos de construcciones diferentes: estructuras transitivas, intransitivas y pronominales. Estas estructuras están organizadas atendiendo a las relaciones metafóricas que se establecen entre los participantes, basadas todas ellas en las nociones de transferencia o movimiento dirigido a un punto, ya sea de forma física o abstracta. Los tres tipos de estructura se diferencian, sin embargo, en el grado de participación activa que desempeña el argumento dativo en cada una de ellas, siendo este más elevado en las construcciones transitivas y disminuyendo según se pasa de estas a las intransitivas, y de ellas, a las pronominales. El grado de participación activa que implica el dativo lo acerca al sujeto; no obstante, lo que le diferencia de este es el carácter agentivo, así pues, mientras que el sujeto está integrado por el argumento agentivo que da pie al desarrollo de la cadena de acción, el dativo representa al participante no agentivo sobre el cual se ajusta el evento o que se ve afectado por este.

En este sentido, se puede mencionar el modelo propuesto por Primus (1999, 55), pues perfila esta idea con más profundidad. La autora sostiene que los papeles de Receptor, Destinatario o Beneficiario, es decir, aquellos representados mediante el dativo, confluyen en el proto-papel que ella denomina Proto-receptor. Este papel se define precisamente por el hecho de que combina rasgos protoagentivos con rasgos propios del Proto-paciente. Por un lado, los Proto-receptores adquieren o pierden propiedades proto-agentivas según el tipo de acción que inicie el Proto-Agente, por ejemplo, en un predicado con el verbo dar, los Proto-receptores se convierten en poseedores; o en uno con el verbo robar, se presupone el rasgo de poseedor en el Proto-receptor, por el hecho de que el evento 
implica precisamente su pérdida. Por otro lado, en lo que respecta a la parte que el Proto-receptor comparte con el Proto-paciente, Primus sostiene que ambos son papeles dependientes del Proto-agente, en el sentido de que su función en el evento depende de la acción que inicia este último. Por todo ello, el modelo de Primus viene a reforzar la posición de cercanía entre Proto-paciente y Proto-receptor o, en términos de caso, entre acusativo y dativo.

Por todo lo expuesto, Delbeque/Lamiroy concluyen que el uso del dativo en español implica una participación en un grado de prominencia más alto que el del acusativo, pero inferior al del nominativo. Esta última observación, sostienen, puede ser de interés para defender la hipótesis de algunos autores según la cual la adquisición lingüística de las funciones o relaciones gramaticales (sujeto, objeto directo, objeto indirecto, etc.) estaría supeditada a la adquisición previa de patrones semánticos asociados cognitivamente con dichas funciones sintácticas, como agentividad para el sujeto o carácter de paciente para el objeto directo. Determinan las autoras que, en el caso del objeto indirecto en español, un candidato cognitivo que presenta un gran potencial podría ser la afectación (Delbecque/Lamiroy 1996, 112).

La propuesta del trabajo que acaba de ser presentado constituye una base fundamental para la interpretación de los resultados obtenidos en los dos experimentos de esta investigación, pues más allá de la animacidad, la definitud/ especificidad o el alto grado de individuación del objeto, es decir, más allá de las características propias del SN, propone la caracterización de los dativos en español a través de un rasgo relacional dependiente de la semántica del verbo: la afectación. Sin embargo, no es la primera que ya apuntaba en este sentido. Recordemos de nuevo en (119) la descripción de los casos profundos que proponía ya Fillmore en términos de afectación, presentada anteriormente en el capítulo 2.

Definición de los casos Dativo y Objetivo (Fillmore 1968, 46-47)

a. Dativo: caso del ser animado afectado por la acción o el estado referido por el verbo.

b. Objetivo: [. . .] caso de cualquier cosa representable por un nombre cuyo papel en la acción o estado referido por el verbo sea identificado por la interpretación semántica del propio verbo; posiblemente el concepto debería estar limitado a cosas que estén afectadas por la acción o el estado referido por el verbo.

Como puede observarse, ambos casos se caracterizan por la afectación del participante del evento al que corresponden y, aunque las definiciones no destacan por su exactitud, de ellas parece desprenderse que la diferencia entre ambos papeles reside en el carácter animado o inanimado del objeto. En esta línea es, 
precisamente, en la que se enmarca también el trabajo que se presenta a continuación de Company Company (2003), en el sentido de que reconoce que los objetos directos animados, individuados y (no menos importante) afectados, se encuentran semánticamente más próximos a los complementos indirectos o dativos que el resto de los objetos directos.

\subsubsection{La «pugna» entre acusativo y dativo: Company Company (2003)}

En la línea que marcaban las autoras del estudio presentado en el subapartado anterior, Company Company (2001; 2002a; 2003; 2006) defiende en diversos trabajos que la dificultad para delimitar los usos del dativo a la que se ha hecho referencia es debida a la inestabilidad del sistema actual de marcado de caso, que evoluciona progresivamente, según la autora, hacia la desaparición del acusativo en español. En (120) aparece recogida la hipótesis de partida de la autora:

(120) Hipótesis de la expansión del objeto directo y del objeto indirecto en español (Company Company 2003, 225)

«Cada vez que en la historia del español el marcado del objeto directo con la preposición a avanza de forma significativa, el objeto indirecto fortalece su condición de objeto mediante el refuerzo de sus mecanismos de marcado, la debilitación del objeto directo o mediante ambos procesos al mismo tiempo». ${ }^{25}$

Company Company sostiene que a nivel diacrónico se ha producido en español una competición entre las funciones de objeto directo e indirecto, o entre los casos acusativo y dativo, por ocupar la posición formal y funcional de objeto. La consecuencia de esta "pugna» ha supuesto la expansión del dativo a diferentes contextos sintácticos más allá de los que ocupaba en latín. Dicha expansión ha alcanzado tal magnitud, según Company Company, que el español se está convirtiendo progresivamente en una lengua que opondrá objeto primario a objeto secundario, en vez de objeto directo frente a indirecto. La autora justifica su posición en el hecho de que el dativo está desarrollando más mecanismos de marcado que el acusativo (como se verá más adelante) y ello, sumado al sincretismo de marcado de caso, implicará que, si el marcado llega a ser único para ambos casos, estos simplemente se diferenciarán atendiendo al grado de prominencia que presenten los distintos objetos. Esta distinción entre lenguas con objeto directo/indirecto frente a lenguas con objeto primario/secundario está basada en el trabajo de Dryer (1986), que defiende que, en las lenguas que oponen objeto primario

25 Traducción propia. 
frente a objeto secundario, el primario se corresponde con el objeto indirecto de las estructuras ditransitivas o con el directo de las transitivas; mientras que el objeto secundario representaría el objeto directo de las ditransitivas. En definitiva, señala Company Company que la marca de dativo terminará imponiéndose como marca genérica de «objeto», provocando la desaparición de la actual oposición de casos.

La autora argumenta que su teoría se sustenta en numerosos cambios que ha experimentado la lengua española y que son realmente la manifestación de un cambio global único: la imposición del dativo como caso para marcar el objeto primario de los verbos o, incluso, como caso único para marcar objetos. Esta serie de cambios a los que Company Company hace referencia son los siguientes: (i) expansión diacrónica del marcador preposicional $a$ a través de la categoría de los objetos directos; (ii) generalización de la duplicación del objeto indirecto; (iii) pérdida del marcador preposicional de los objetos directos humanos en oraciones ditransitivas; (iv) flexibilización semántica del dativo; (v) despronominalización del clítico dativo; (vi) marcación anómala del dativo en el clítico acusativo; (vii) generalización del leísmo; e (viii) invasión progresiva del dativo como sujeto causado en las construcciones causativas $(2003,227)$. A continuación, se ha realizado una breve descripción de cada uno de ellos con el fin de llegar a entender hasta qué punto se aproximan los objetos directos con MDO y los objetos indirectos.

El primero de los cambios ya ha sido señalado en el primer apartado de este capítulo y se describe con mayor precisión en el capítulo 3. Este cambio supone la progresiva expansión del MDO atendiendo a las escalas de animacidad y definitud/especificidad, y desde su mismo comienzo implica el acercamiento de los casos acusativo y dativo debido al progresivo sincretismo que se da entre la manifestación morfológica en los objetos directos marcados y la de los objetos indirectos. Este cambio está relacionado a su vez con la generalización de la duplicación pronominal del dativo. Al aumentar el acusativo su ámbito de marcado preposicional, el dativo extiende a su vez el mecanismo de duplicación pronominal para seguir manteniendo de alguna manera su posición frente al acusativo. Así, en el estudio diacrónico llevado a cabo por Company Company (2003, 230), los dativos duplicados pronominalmente pasan de suponer el 6\% (22/343) de los casos en el siglo XIII, al 83\% (505/609) en el siglo Xx.

En lo que respecta a la pérdida del MDO en los objetos directos humanos de las oraciones ditransitivas, este es producto de la concurrencia de dos argumentos de características inherentes similares, es decir, dos argumentos con referentes humanos. El objeto directo tiende a aparecer sin la marca preposicional en este tipo de contextos, lo que se puede interpretar como una degradación de este en favor del objeto indirecto. Este hecho se puede apreciar tanto en (121a) como en (121b), donde la aparición del MDO resulta extraña; no obstante, la marca 
preposicional resulta más aceptable si el objeto indirecto aparece duplicado con el pronombre correspondiente, lo que indica que el reforzamiento del indirecto posibilita la marca del objeto directo, al no encontrarse ya ambos objetos al mismo nivel. Este último hecho es el que reflejan los ejemplos de (121a') y (121b').

(121) Construcciones ditransitivas (Company Company 2003, 235-236)

a. el maestro presentó (??a) su mujer a sus alumnos.

a'. el maestro les presentó (a) su mujer a sus alumnos.

b. el cacique entregó (??a) su hija a los conquistadores.

b'. el cacique entregó (a) su hija a los conquistadores.

El efecto de bloqueo que experimenta el MDO en el objeto directo de las construcciones ditransitivas ha sido comprobado de manera cuantitativa por diversos estudios diacrónicos (Ortiz Ciscomani 2011; von Heusinger 2018; entre otros).

En cuarto lugar, Company Company señala la flexibilización semántica del dativo. Este cambio hace referencia al aumento de la tolerancia que presenta el caso respecto al tipo de sintagmas en los que puede aparecer codificado. Así, mientras que los objetos indirectos no humanos codificados mediante un SN léxico constituían tan solo el 13\% (46/343) en el siglo XIII, en el siglo XIX ya ascendían al 37\% (172/464). Este hecho refleja la expansión del dativo sobre la categoría de los inanimados, al poder desempeñar progresivamente papeles semánticos que anteriormente les estaban vetados.

En lo que respecta a la despronominalización del clítico dativo, es un mecanismo por el que el pronombre dativo singular pasa de mostrar concordancia con el objeto indirecto, a mostrarla con el verbo (aunque siga haciendo referencia al indirecto). Se convierte por lo tanto en un afijo que marca la concordancia objetoverbo, característica típica de las lenguas de objeto primario/secundario; y es que el dativo/Receptor, y no el acusativo/Paciente, es el que controla el marcado de concordancia verbo-objeto. Casos como los de (122) reflejan este cambio cada vez más extendido, pues, atendiendo a los datos de Company Company (2003, 230), el clítico de dativo para hacer referencia a objetos indirectos en plural ha pasado de mostrar concordancia de número en un 100\% (9/9) de los casos durante el siglo XIII, a tan solo un 43\% (144/333) en el siglo xx.

(122) Despronominalización del clítico dativo (Company Company 2003, 237)

a. esclame usted con Eneas avisándole a sus compañeros.

b. a las telenovelas le hemos agregado un público no tradicional.

Otro cambio que parece reflejar la prominencia del caso dativo y la extensión funcional del mismo es el marcado anómalo del dativo sobre el clítico de acusa- 
tivo. En español, cuando una oración como la de (123a) contiene tanto un objeto directo como uno indirecto y ambos se pronominalizan, como ocurre en (123b), el clítico de dativo adopta la forma invariable se, que no muestra la concordancia de número que mostraría el pronombre le. No obstante, algunas variedades (fundamentalmente variedades americanas y el español canario) han desarrollado un mecanismo mediante el cual el clítico de acusativo pasa a reflejar determinados rasgos del dativo dependiendo de la variedad. En algunos casos, el clítico de acusativo acoge los rasgos de concordancia de número del dativo simplemente, como en (123c); en otros, los de número y género, como ocurre en (123d); y en determinadas variedades puede llegar a aparecer directamente la forma dativa, en sustitución del acusativo, como refleja (123e). Así pues, el clítico de acusativo en estas variedades pasa a convertirse en un mero alojamiento fonológico para exhibir los rasgos del dativo.

(123) Marcado anómalo de la concordancia del dativo sobre el acusativo (Company Company 2003, 241-242)
a. Juan compró una bicicleta a sus hijas.
b. Juan se la compró.
c. el poco tiempo que me queda estoy con mis hijos y se los entrego total- mente a ellos.
d. si ellas me quieren comprar el caballo, yo se las venderé.
e. el cesto se les he regalado a unos chicos.

Por lo que se refiere al leísmo, este cambio ha sido posiblemente el más ampliamente estudiado en el orden de mecanismos que contribuyen a la expansión del caso dativo, en detrimento del acusativo. El leísmo supone la utilización del pronombre clítico dativo en sustitución del acusativo en oraciones monotransitivas, tal como reflejan los casos de (124); sin embargo, no todas las variedades presentan la misma extensión del fenómeno, pues mientras que la aceptación de (124a) está más o menos generalizada, no es este el caso de (124b), cuya aceptación se reduce solo a algunas variedades.

\section{(124) Leísmo}

a. Ha pasado su hermano por delante de él y no le ha visto.

b. Para concentrarte, deja el móvil y apágale.

El leísmo es un fenómeno presente en numerosas variedades del español, no solo en España, sino también en variedades americanas (con independencia de los contextos a los que se extienda). Si bien es cierto que se trata además de un cambio aceptado normativamente en casos como los de (124a), donde el pronom- 
bre hace referencia a un objeto humano masculino y en singular, no ocurre esto cuando el objeto al que hace referencia el pronombre es inanimado, como refleja el ejemplo de (124b), femenino o plural. En todos estos casos la norma desaconseja su uso; no obstante, el leísmo ha seguido su expansión hacia estos contextos.

Por oposición al leísmo, y en contra de la hipótesis de Company Company, habría que mencionar la existencia del laísmo y el loísmo, pero ante estos casos la autora argumenta que los datos diacrónicos reflejan un uso marcadamente inferior tanto del laísmo como del loísmo frente al uso del leísmo. Asimismo, su extensión geográfica se ha reducido siempre a tan solo algunas variedades del centro y norte peninsular en España, por lo que no podría hablarse de un cambio que se haya generalizado en el conjunto de la lengua, como sí apunta la evolución del leísmo.

Por último, señala Company Company, dentro del conjunto de cambios que favorecen la expansión del dativo frente al acusativo, la invasión progresiva del caso dativo como sujeto de las construcciones causativas. En latín, el sujeto de este tipo de construcciones siempre se codificaba utilizando acusativo, pues pertenecía a las llamadas construcciones de acusativus cum infinitivo. En la evolución del latín a las distintas lenguas romances, las causativas comenzaron a seleccionar dativo para el sujeto de la causativa si el verbo que este introducía era transitivo, y mantuvieron el acusativo si el verbo era intransitivo. Este hecho se puede apreciar en lenguas como el italiano y el francés, tal como demuestran los ejemplos de (125a), donde el dativo se utiliza para introducir una causativa transitiva; o (125b), donde el acusativo es el caso que se emplea para introducir una causativa intransitiva.

(125) Caso del sujeto en las construcciones causativas (Company Company 2003, 245)

a. j'ai fait manger la pomme à Claude > je lui ai fait manger la pomme.

lui - sujeto causado en DAT; manger - infinitivo subordinado transitivo 'Yo hice a Claudio comerse la manzana.'

a'. faccio mangiare la mela al bimbo > Gli faccio mangiare la mela. gli - sujeto causado en DAT; manger - infinitivo subordinado transitivo 'Yo hice al niño comerse la manzana.'

b. j'ai fait aller Claude > je l'ai (le ai) fait aller.

le - sujeto causado en ACC; aller - infinitivo subordinado intransitivo 'Yo hice ir a Claudio.'

b'. Gianni fa venire Paolo > Gianni lo fa venire.

lo - sujeto causado en ACC; venire - infinitivo subordinado intransitivo 'Juan hizo venir a Pablo.' 
El español, por su parte, ha permitido la utilización del dativo para marcar el sujeto causado de verbos intransitivos desde época muy temprana, como puede apreciarse en (126a). No obstante, (126b) es la muestra de que también es posible encontrar la invasión de caso en el sentido opuesto, es decir, la utilización del acusativo para marcar sujetos causados de verbos transitivos; sin embargo, este hecho se ha producido con una frecuencia acusadamente inferior. Como señala Alfonso (1998) en su estudio diacrónico, entre los siglos XIII y XV, tan solo el 8\% (15/184) de los sujetos causados con verbo transitivo aparece en acusativo, frente al 43\% (60/138) de los sujetos causados con verbo intransitivo que aparece en dativo.

(126) Caso del sujeto en las construcciones causativas en español (Company Company 2003, 246)

a. e descendieron a el e besaronle las manos e fizieronle cavalgar en aquel palafrén (s. XIV)

b. Fizo los a todos yurar quel ayudassen a deffender Roma (s. XIII)

Por lo tanto, se podría decir que el cambio en español ha tenido dos etapas de refuerzo: la primera, la introducción del dativo con los verbos transitivos como hicieron el resto de lenguas románicas; y la segunda, la ampliación del dativo a los verbos intransitivos.

En definitiva, la hipótesis de Company Company presentada en (120) parece confirmarse al observar que el conjunto de cambios descritos, relacionados con la dicotomía de caso acusativo/dativo, evidencia una tendencia generalizada hacia la extensión del dativo en español; no obstante, el objetivo de la presente investigación no es tan ambicioso como el del trabajo de Company Company y no se pretende demostrar la conversión del español en una lengua de objeto primario y objeto secundario, como defiende la citada autora. La pretensión de este trabajo, por el momento, se reduce a mostrar una vez más con diferentes argumentos, la marcada cercanía que existe en español entre objeto directo con MDO y dativo $u$ objeto indirecto, pues como se puede extraer del trabajo de Company Company ambos tipos de argumentos se caracterizan, más allá de la animacidad y la definitud, por su marcado «carácter de objetos prominentes» dentro del evento o, recuperando las palabras de Delbecque/Lamiroy, por su carácter de objetos afectados.

\subsubsection{Los objetos afectados como «receptores de fuerza»: Jackendoff (1990) y Cruse (1991)}

Llegados a este punto, es importante destacar que, para hablar de la afectación como noción que comparten en cierta medida el objeto directo y el indirecto, es necesario optar por una definición del término amplia, que permita recono- 
cer como afectados argumentos más allá de aquellos que poseen el papel de Paciente. En el capítulo 2, se señalaba que a grandes rasgos se podían agrupar todas las descripciones del concepto de afectación en dos grandes bloques: aquellas que equiparan afectación a la noción de cambio de estado y aquellas otras que relacionan el concepto con la noción de recepción de una fuerza. Como hemos mencionado, ambas líneas de trabajo daban como resultado predicciones similares respecto a la afectación del objeto/Paciente. Beavers, que es quien desde la perspectiva del cambio de estado más ha ampliado el concepto, defendía que con cierto tipo de verbos (los que implican potencialmente la afectación del objeto), un argumento se podía considerar afectado, no tanto por alcanzar un estado resultante tras la realización del evento, sino por la mera posibilidad de experimentar un cambio. Esta visión coincidía con las predicciones llevadas a cabo desde la otra perspectiva. Las propuestas de Jackendoff (1990) y Cruse (1991), basadas en el concepto de dinámica de fuerzas (Talmy 1976; 1988; 2000), definían el objeto afectado como aquel participante, distinto del Agente, que recibía de alguna forma la fuerza ejercida por el Agente o Actor a través de la acción denotada por el verbo. Así pues, los objetos afectados tanto desde una perspectiva como desde la otra presentaban la capacidad de responder adecuadamente a la prueba de afectación presentada nuevamente en (127). Atendiendo a dicha prueba, se consideran afectados aquellos SN con la capacidad de aparecer en el siguiente marco sin que la estructura resulte anómala:

$$
\begin{aligned}
& \text { Prueba de afectación (Jackendoff 1990, 125) } \\
& \left\{\begin{array}{l}
\text { Lo que le ocurrió } \\
\text { Lo que x le hizo }
\end{array}\right\} \text { a SN fue... }
\end{aligned}
$$

No obstante, en lo que se refiere a los objetos indirectos/dativos es donde surge la discrepancia entre ambos enfoques. Por un lado, Beavers (2010; 2011) reduce la noción de afectado a todos aquellos objetos que puedan experimentar un cambio de estado implicado por la propia semántica léxica del verbo, y a esta definición escapan, por tanto, los objetos indirectos, cuyos papeles temáticos más comunes suelen ser los de Destinatario o Beneficiario. Para defender esta idea se basa en los verbos ditransitivos de posesión causada (dar, regalar, enviar...). Con este tipo de verbos reconoce que el Tema, el objeto directo, sí puede considerarse afectado, pues experimenta un cambio, entendido este como un movimiento o cambio de posición; sin embargo, el caso del Destinatario es diferente. Este último, codificado por el dativo generalmente, no provoca un resultado del todo anómalo en la prueba de afectación, como puede observarse en (128). Beavers apunta que este hecho se debe a la posible afectación psicológica que puede recibir el partici- 
pante tras la recepción del tema, pero que dicha afectación se infiere de manera pragmática y no está, por tanto, codificada en el significado del verbo; a pesar de ello, deja abierta la posibilidad de que existan otros tipos de afectación más allá de los definidos estrictamente por la noción de cambio de estado, que puedan incluir a los Destinatarios. ${ }^{26}$

(128) Afectación en los verbos de posesión causada (Beavers 2010, 19)

a. Juan dio el perro a María.

b. Lo que le ocurrió al perro es que Juan se lo dio a María.

c. Lo que le ocurrió a María fue que Juan le dio un perro.

Por otro lado, el enfoque basado en la dinámica de fuerzas sí permite dar una explicación de los Destinatarios en términos de afectación. Como ya se ha señalado en el capítulo 2, este enfoque es el que subyace a los modelos de descripción de eventos de Jackendoff (1990) y Croft (1991), entre otros, que están inspirados, a su vez, en la noción cognitiva de dinámica de fuerzas acuñada por Talmy (1976) (véase subapartado 2.2.7.2). Desde esta perspectiva, la afectación queda sencillamente definida como la condición de ser «receptor de una fuerza». Así pues, en un evento en el que hay implicados más de un participante, cada participante en el evento se puede definir como afectado en cierta medida a excepción del primero (Agente/Actor), ya que la cadena de causalidad se define a través de la transferencia de fuerza y, por lo tanto, todos los participantes son receptores de fuerza a excepción del primero. Rappaport-Hovav/Levin $(2001,787)$ señalan, como ya se comentó, que la prueba de Jackendoff, más que una prueba de la «condición de Paciente» que presenta un argumento (que es para lo que él la propone), lo que identifica son receptores de fuerza, pues los verbos cuyos argumentos no pueden ser calificados como receptores de fuerza son precisamente los que no pueden aparecer en este contexto, tal como se aprecia en (129).

(129) Argumentos que no actúan como receptores de fuerza (Rappaport-Hovav/ Levin 2001, 787)

a. Ellos siguieron la estrella.

\#Lo que le ocurrió a la estrella fue que ellos la siguieron.

\#Lo que ellos le hicieron a la estrella fue seguirla.

b. Ellos vieron un coche.

\#Lo que le ocurrió al coche fue que ellos lo vieron.

\#Lo que ellos le hicieron al coche fue verlo.

26 Nota 18 a pie de página en Beavers $(2010,19)$. 
Estos ejemplos demuestran que no todos los eventos implican una transmisión de fuerza; de hecho, los verbos de percepción, como ver en (129b), representan un caso atípico de trasferencia de fuerza simétrica: se puede afirmar que el estímulo percibido ejerce una influencia en el perceptor (Experimentante) que provoca en este un cambio en su estado mental, mientras que, por otro lado, el perceptor tiene que centrar su atención sobre el estímulo. Así pues, con estos verbos no se puede designar a ninguno de los participantes en el evento como el receptor de fuerza y, por ello, no se puede destacar a ninguno de ellos en términos de afectación. Jackendoff reconoce que este tipo de verbos suponen un problema para el enfoque basado en la dinámica de fuerzas y, de hecho, lleva a cabo algunas modificaciones en sus análisis más actuales sobre este problema; sin embargo, en lo que a esta investigación concierne, no es necesario entrar en el dilema teórico y partiremos de la base de que los verbos de percepción no implican afectación, tal y como reconocen los dos enfoques principales y como ratifica la prueba de (127).

En definitiva, ateniéndonos a una noción de afectación más amplia, entendida como la condición de ser receptor de una fuerza, es posible defender que los objetos indirectos/dativos pueden considerarse participantes afectados por la acción del verbo. Los ejemplos de (130) representan diversos usos del dativo. La oración de (130a) muestra un ejemplo prototípico de posesión causada, es decir, el Agente provoca la transmisión de un elemento al Destinatario/Beneficiario. Según Beavers $(2010,19)$, la oración no resulta del todo anómala o puede resultar aceptable debido al posible cambio psicológico que el evento podría provocar en el Receptor, pero, en cualquier caso, dicho cambio tendría que inferirse pragmáticamente; sin embargo, según el enfoque basado en la dinámica de fuerzas, la condición de afectado del objeto indirecto vendría dada por el hecho de que el objeto transferido, que antes no estaba bajo su dominio, ahora sí lo está. En términos de transferencia de fuerzas, el verbo dar implica una transferencia en el sentido más físico del propio término: el Agente provoca el traslado del Tema de su dominio (el del Agente) al dominio del Destinatario y es, precisamente, la recepción del Tema lo que provoca la afectación del Destinatario. En (130b) se presenta un evento similar, con la particularidad de que la transferencia es abstracta (contar un cuento). (130c) por su parte contiene un Tema que constituye una fuerza en sí misma y, por lo tanto, la afectación del Destinatario se aprecia de forma clara. Finalmente, el caso de (130d) es un tanto distinto, pues constituye un uso especial del dativo denominado dativo posesivo; no obstante, representa el uso del dativo en el que quizá se aprecia de manera más evidente la afectación del objeto indirecto. 
(130) El objeto indirecto como argumento afectado

a. Juan dio un regalo a Luis.

Lo que le ocurrió a Luis fue que Juan le dio un regalo.

Lo que Juan le hizo a Luis fue darle un regalo.

b. Juan contó un cuento a Luis.

Lo que le ocurrió a Luis fue que Juan le contó un cuento.

Lo que Juan le hizo a Luis fue contarle un cuento.

c. Juan dio una patada a Luis.

Lo que le ocurrió a Luis fue que Juan le dio una patada.

Lo que Juan le hizo a Luis fue darle una patada.

d. Juan cortó un dedo a Luis.

Lo que le ocurrió a Luis fue que Juan le cortó un dedo.

Lo que Juan le hizo a Luis fue cortarle un dedo.

La noción de afectación asociada al dativo no es una idea que se haya explorado únicamente desde un punto de vista cognitivo. Precisamente para el español existen algunos estudios de corte sintáctico que serán mencionados a continuación. Estos trabajos están orientados, en general, al estudio de la llamada alternancia de dativo que se produce en estructuras como las de (131). Demonte (1995) se refiere a los dativos, como los de (130d-f), que aparecen duplicados por el pronombre clítico, como objetos secundarios afectados o dativos afectados. La autora defiende que este tipo de estructuras son equivalentes a las construcciones de doble objeto en inglés (ej. Mary sent her sister a letter 'María envió una carta a su hermana'). Según asume Demonte, la aparición del pronombre clítico provoca el ascenso de estos dativos, a diferencia de los que aparecen sin duplicar, a una posición superior a la del objeto directo en la estructura sintáctica y ello implica que adquieran una lectura afectada.

(131) Alternancia de dativo (Demonte 1995, 6)

a. Entregué las llaves al conserje.

b. Cociné el pollo a Mario.

c. Limpié las manchas a la camisa.

d. Le entregué las llaves al conserje.

e. Le cociné el pollo a Mario.

f. Le limpié las manchas a la camisa.

No obstante, siguiendo el enfoque propuesto en lo que a la afectación se refiere, es difícil reconocer la diferencia de afectación en el dativo entre los casos duplicados y aquellos no duplicados. El problema fundamental reside en que la aplicación de la prueba de afectación requiere de la duplicación pronominal, como 
se muestra en (132a-b); y, por lo tanto, no se puede establecer la distinción mencionada por Demonte, pues al intentar aplicar la prueba sin duplicación pronominal, la estructura resulta anómala, como se aprecia en (132c-d).

(132) Prueba de afectación a estructuras con alternancia de dativo

a. Lo que le ocurrió al conserje fue que le entregué las llaves.

b. Lo que yo le hice al conserje fue entregarle las llaves.

c. \#Lo que le ocurrió al conserje fue que entregué las llaves.

d. \#Lo que yo le hice al conserje fue entregar las llaves.

En lo que se refiere a los dativos posesivos, de los que ya se ha mencionado que constituyen un tipo de dativo con características un tanto especiales, su uso se ha relacionado con la noción de afectación con más claridad si cabe que en el resto de casos. Este tipo de dativos denota el poseedor del argumento interno del predicado, ya sea este el objeto directo (como en (133a)) o el sujeto (como en (133b)).

(133) Dativo posesivo (Sánchez López 2007, 153)

a. El gato le arañó la cara.

b. A Juan le duele el brazo.

Sánchez López $(2007,171)$ propone que la lectura posesiva del dativo es el resultado de la relación que se establece con un predicado locativo. Como se manifiesta en (134), el argumento dativo constituye, de hecho, un predicado locativo en una relación parte-todo con otro argumento de la oración. Lo que la autora defiende es que los predicados de afectación pueden seleccionar una predicación locativa como argumento interno y dicha predicación locativa puede tomar dos formas diferentes atendiendo a la posición argumental de los elementos en una relación parte-todo. Si el SN que hace referencia a la parte en cuestión (la mano) no implica la afectación completa de la parte, este permanece como sintagma que señala simplemente la «parte implicada»; sin embargo, si dicho sintagma hace referencia a una parte que queda completamente afectada por la acción verbal, entonces este aparecerá en acusativo como parte central de la predicación locativa y el sintagma que hace referencia «al todo» quedará codificado en dativo.

(134) Alternancias propias del dativo posesivo

a. Juan cortó en la mano a Luis. > Juan lo cortó en la mano.

b. Juan cortó la mano a Luis. > Juan le cortó la mano. 
No obstante, el hecho de que «el poseedor» de la parte implicada quede codificado en dativo, no cambia para nada su condición de afectado atendiendo al resultado que arroja la prueba de afectación. Pues, tal como se observa en (135b), frente al ejemplo de (135a), la afectación completa de la parte implicada se percibe incluso con una mayor afectación también en el poseedor.

(135) Prueba de afectación con dativos posesivos

a. Lo que le ocurrió a Luis fue que Juan lo cortó en la mano.

Lo que Juan le hizo a Luis fue cortarlo en la mano.

b. Lo que le ocurrió a Luis fue que Juan le cortó la mano.

Lo que Juan le hizo a Luis fue cortarle la mano.

Este apartado ha explorado la estrecha relación que existe entre MDO y dativo, sosteniendo que la proximidad entre ellos no se debe tan solo al grado de animacidad y/o definitud que define ambos casos, sino también al grado de afectación que presentan los objetos codificados mediante ellos. El efecto que estos tres factores ejercen sobre el objeto directo aparece codificado en numerosas lenguas mediante el MDO, como ya se ha explicado anteriormente. Sin embargo, el objeto indirecto en español presenta siempre la marca preposicional y, por lo tanto, es imposible distinguir, en principio, los diferentes grados en que animacidad, definitud y afectación pueden presentarse atendiendo a la morfología del propio objeto. No obstante, esto no es lo que ocurre en todas las lenguas, por lo que es esperable que aquellas lenguas cuyo objeto indirecto no aparezca codificado de manera uniforme manifiesten de alguna manera el efecto de los factores mencionados; y precisamente este es el hecho que muestra Kittilä (2007) en su estudio.

Este autor lleva a cabo un estudio tipológico de cómo algunas lenguas codifican en el objeto indirecto determinados rasgos que contribuyen a definir el grado de transitividad de una oración. Entre ellos, se encuentran la animacidad, la definitud y la afectación, que, en definitiva, son aquellos rasgos que hemos visto que acercan semánticamente al MDO y al dativo.

En lo que concierne a la animacidad, uno de los ejemplos que pone Kittilä es el del finés, reproducido aquí en (136). Esta lengua se vale del caso adlativo para expresar las Metas animadas (humanas), mientras que recurre al ilativo para codificar las metas inanimadas.

(136) Codificación de la animacidad en el objeto indirecto (Kittilä 2007, 156)
a. lähetti
lähett-i
lähettime- $n$
poja-lle
mensajero.NOM enviar-3SG.PAST transmisor-ACC chico-ALL
'El mensajero envió el/un transmisor al chico.' 
b. lähetti lähett-i lähettime-n lähetystö-ön mensajero.NOM enviar-3SG.PAST transmisor-ACC embajada-ILL 'El mensajero envió el/un transmisor a la embajada.'

La definitud/especificidad, asimismo, aparece reflejada en la forma de codificar los objetos indirectos de algunas lenguas, como por ejemplo el wolaita, una lengua omótica hablada en el sur de Etiopía, que como se aprecia en (137b) codifica en acusativo las Metas definidas, mientras que se vale del absolutivo o caso no marcado para hacer referencia a las indefinidas tal y como muestra (137a).

(137) Codificación de la definitud en el objeto indirecto (Kittilä 2007, 150)

a. 'astamareé mat'aápaa mat'aáfa keettá yedd-iisi maestro.M.NOM libro.M.ACC libro casa.ABS enviar-3M.SG.PERF 'El profesor envió el libro a una biblioteca.'

b. 'astamareé mat'aápaa ba biir-úwa maestro.M.NOM libro.M.ACC 3LOG despacho-M.ACC yedd-iisi enviar-3M.SG.PERF 'El profesor envió el libro a su despacho.'

Finalmente, al igual que la animacidad y la definitud, Kittilä señala que algunas lenguas codifican en el complemento indirecto la afectación. Este hecho constituye un importante argumento que apoya la idea que se está defendiendo en este apartado de que la afectación es también un rasgo presente en los objetos indirectos/dativos. En Alamblak, lengua Sepik-Ramu hablada en el distrito de Sepik en Papúa-Nueva Guinea, la Meta toma la forma de un adjunto, siempre y cuando su referente no quede afectado de forma dramática por la acción denotada por el verbo, como ocurre en (138a); sin embargo, este mismo papel, la Meta, pasa a constituir un argumento y constituye el objeto directo de la oración cuando la acción del verbo provoca su afectación.

(138) Codificación de la afectación en el objeto indirecto (Bruce 1984, 238 apud Kittilä 2007, 153)

a. yima-r kahpa-m nanho met-t-n persona-3sG.m aceite-3PL mi mujer-3SG.F-S.SET

hëta-më-r-m echar.REC.PAST-3SG.M-3PL

'Un hombre echó aceite a mi mujer' (implicación: el aceite no le afectó) 


\author{
b. yima-r nanho met-t kahpa-m \\ persona-3SG.M mi mujer-3SG.F aceite-3PL \\ hëta-më-r-t \\ echar-REC.PAST-3SG.M-3SG.F \\ 'Un hombre echó aceite a mi mujer' (implicación: el aceite le afectó)
}

Este ejemplo nos lleva a pensar que quizá sí se pueda establecer un paralelismo en español en cuanto a la realización como argumento o adjunto tanto del objeto directo como del indirecto, atendiendo al grado de afectación que se les supone tras la realización del evento. Los ejemplos de (139a) demuestran que mientras hacia el oso no implica que el disparo alcanzase al oso, al oso, sí que implica el alcance del disparo emitido; por consiguiente, en (139a) lo que encontramos es la Meta codificada en forma de adjunto, mientras que en (139a'), donde el objeto queda afectado, este toma forma de objeto directo. De la misma forma, esta situación es aplicable al objeto indirecto. La interpretación que se obtiene de (139b) es que María echó el agua en las plantas bien por accidente o simplemente para deshacerse de ella; sin embargo, de (139b') se desprende una lectura que implica cierta intención de conseguir algún tipo de efecto en las plantas, es decir, una interpretación similar a la que habríamos obtenido de una oración como María regó las plantas. Por todo ello, en (139b) la Meta aparece codificada en forma de adjunto, mientras que en (139b') la Meta/Receptor del evento se materializa como el objeto indirecto.

(139) Codificación de los receptores como argumentos/adjuntos en español

a. El cazador disparó hacia el oso.

a'. El cazador disparó al oso.

b. María echó agua en las plantas.

b'. María echó agua a las plantas.

En resumen, este apartado se ha adentrado en las semejanzas que existen entre el acusativo con MDO y el dativo con el propósito de demostrar que, más allá de la animacidad y la definitud o la individuación, la afectación constituye asimismo un rasgo fundamental que define en cierta manera ambos tipos de constituyentes. Este hecho ha conducido a la necesidad de establecer una definición de afectación que fuese capaz de captar el efecto de este factor sobre el dativo/objeto indirecto, fundamentalmente, porque, como se ha visto, son numerosos los estudios y las perspectivas que relacionan el dativo con la noción de afectación; sin embargo, un aspecto sobre el que aún no se ha indagado es la explicación de cómo se aplica esta similitud de los rasgos que definen a ambos objetos para la explicación del MDO. 


\subsection{El MDO en español: un fenómeno basado en relaciones de prominencia}

Los apartados previos han servido para argumentar la proximidad semántica existente entre los objetos directos con MDO y los dativos/objetos indirectos, $\mathrm{y}$ producto de esta indagación han sido tres los rasgos que se han puesto de manifiesto como explicación de dicha proximidad: animacidad, definitud/especificidad y afectación.

El presente apartado propone una explicación para el MDO en español en términos cognitivos, atendiendo a las nociones de transmisión de fuerza y prominencia. Partiendo de la idea de cadena causativa, la propuesta se basa en la justificación del MDO como señal de un elevado grado de prominencia semántica en el objeto directo. Dicho grado se define teniendo en cuenta los rasgos de animacidad, definitud y afectación.

Con el objetivo de desgranar esta idea, el apartado está dividido, a su vez, en dos subapartados: en el primero se describe cuál es la noción de prominencia que se maneja en la propuesta, de forma que sea posible establecer qué se entiende por argumento prominente; en el segundo, se aplica la noción de prominencia al fenómeno del MDO en español.

\subsubsection{El concepto de prominencia}

La noción de prominencia es un concepto sumamente extendido entre las ciencias cognitivas, la psicología, la filosofía y la lingüística, disciplina, esta última, donde se ha relacionado muy a menudo con la noción de atención en sus diversas dimensiones. Sin embargo, existe la idea entre los lingüistas de que es necesario distinguir con claridad la prominencia lingüística, entendida como un principio que opera sobre los diferentes sistemas lingüísticos, del sistema atencional, como sistema cognitivo general. No obstante, dentro de la propia lingüística, la noción de prominencia ha sido utilizada en una gran variedad de subdisciplinas y desde muy diversos enfoques. Esto ha dado lugar a una gran dispersión en cuanto a la conceptualización del término, y ha provocado que hoy en día no exista una definición consensuada acerca de qué es lo que implica este concepto.

En el ámbito de la sintaxis y la semántica, que es en el que se enmarca esta investigación, la prominencia ha sido asociada con frecuencia a una serie de escalas o jerarquías, que son las que se han ido mencionando a lo largo de este trabajo (animacidad, definitud/especificidad o papel temático, entre otras); aun así, es importante que, partiendo de que no existe una definición detallada y consensuada para el concepto de prominencia, se intente establecer unos puntos de 
partida que cubran el mayor número de manifestaciones posibles de este fenómeno a través de las diferentes subdisciplinas lingüísticas. Así pues, la prominencia lingüística se puede definir atendiendo a los tres criterios operativos presentados a continuación en (140):

(140) Definición de prominencia (Himmelmann/Primus 2015)

1) La prominencia es una propiedad relacional que destaca a un elemento dentro un conjunto de elementos del mismo tipo.

2) Los elementos prominentes son estructuralmente atractores, es decir, funcionan como anclaje de estructuras mayores de las que son constituyentes y/o posibilitan más operaciones que sus competidores.

3) La prominencia de los diferentes elementos está sujeta al contexto y varía con este.

Ahora bien, antes de pasar directamente al modo en que esta definición se aplica al caso concreto del MDO en español, es necesario especificar la forma en que operan las relaciones de prominencia atendiendo a cada uno de los factores involucrados en el fenómeno. Como ya se ha ido viendo a lo largo de este trabajo, no todos los rasgos asociados al marcado preposicional poseen la misma naturaleza: la animacidad y la definitud/especificidad son características que definen al objeto independientemente de la relación que este mantiene con el resto de los componentes de la oración; por otro lado, la afectación se define como un rasgo relacional que surge de la condición que adquiere un argumento dentro de un determinado evento. A esta última, hay que añadirle la agentividad, rasgo que no ha sido central en esta investigación, pero que, como se mencionaba en el capítulo 2, es asimismo relevante para la explicación del MDO. Por lo tanto, atendiendo a su naturaleza, se encuentran, por un lado, la animacidad y la definitud $\mathrm{y}$, por otro, la agentividad y la afectación.

Animacidad y definitud contribuyen a la condición de afectado de un argumento atendiendo a las escalas de implicación mediante las que se conceptualizan ambas características. De esta forma, un determinado argumento será más prominente cuanto más a la izquierda se sitúe la categoría que lo define en dichas escalas (recuperadas ahora en (141) y (142)).

(141) Escala de animacidad (Comrie 1989, 185; Aissen 2003, 437)

humano $>$ animado $>$ inanimado

(142) Escala de definitud/especificidad (Aissen 2003, 437) pronombres personales $>$ nombres propios $>$ SN definidos $>$ SN indefinidos específicos $>$ SN indefinidos no específicos 
Por lo tanto, un argumento como el niño es más prominente que el perro y este, a su vez, es más prominente que uno como el jarrón. De la misma forma, es más prominente un argumento constituido por un pronombre personal, como ella, que uno constituido por un nombre propio, del tipo María, o que uno integrado por un SN definido, como el niño.

En lo que se refiere a la afectación y la agentividad, estos rasgos dependen, como se ha dicho, de las relaciones que, a partir de la semántica léxica del verbo, se establecen entre sus distintos argumentos. La afectación se ha descrito como la propiedad que presentan todos aquellos argumentos que forman parte de la cadena de fuerza que implica la acción descrita por el verbo, a excepción del Actor/Proto-agente que es quien la genera. Por lo tanto, es una propiedad que afecta fundamentalmente a los objetos directo e indirecto, en mayor o menor medida, como se ha señalado en el apartado anterior. Un objeto afectado constituye dentro del evento un argumento más prominente que uno no afectado; así, el objeto directo de (143a) se considera más prominente que el de (143b).

(143) Prominencia y afectación

a. El policía golpeó a un ladrón.

b. El policía vio un ladrón.

La agentividad, por su parte, es una propiedad cuya gradación ha sido descrita con más detalle. Afecta a todos los argumentos que conforman el evento y atiende al número de características proto-agentivas que recibe cada uno de ellos (véase apartado 2.2.5). Según se desprende del principio de selección argumental de Dowty $(1991,576)$, de entre todos los argumentos candidatos a desempeñar la función de sujeto, el argumento que más rasgos proto-agentivos presente será el que lleve a cabo dicha función. Así pues, se puede afirmar que un argumento más agentivo es más prominente que uno menos agentivo. Tanto en (143a) como en (143b), el policía es un argumento más prominente que el ladrón y, aunque en (143a) el primero de ellos presenta un mayor número de rasgos proto-agentivos que en (143b), en ambos casos dicho número de rasgos es, en cualquier caso, superior al que presenta el ladrón y, por ello, la distribución de funciones sintácticas se mantiene.

Este es muy a grandes rasgos el concepto de prominencia que maneja este trabajo y la manera en que cada uno de los rasgos mencionados contribuye a las relaciones de prominencia en la oración. En el siguiente subapartado, se expone cómo afecta este sistema de rasgos y relaciones de prominencia al caso concreto del MDO en español. 


\subsubsection{Prominencia y MDO}

Según el enfoque que propone este trabajo, el MDO en español es, ante todo, un marcador de prominencia relacionado con la condición de objeto, entendido este en un sentido amplio, que abarca tanto objetos directos como indirectos; o en términos de Lazard (2003), entendido como cualquiera de los actantes que se encuentran dentro de lo que él denomina «zona de objeto». ${ }^{27}$ Esto significa que, de las dos funciones que han sido propuestas en la bibliografía previa, la más presente en este fenómeno es la indexadora o codificadora, pues la marca preposicional señala aquellos argumentos que presentan una serie de características que los hacen prominentes. No obstante, la función desambiguadora tampoco está ausente en su totalidad del fenómeno, aunque esta actúa aparentemente solo en condiciones excepcionales, como se expondrá más adelante.

Para poder observar cómo la marca preposicional se comporta como un marcador relacionado con la condición de objeto, es decir, con el conjunto de rasgos que definen tanto a acusativos con MDO como a dativos, a lo largo de las siguientes líneas se explorarán primero las estructuras con un solo argumento interno y, posteriormente, aquellas que poseen dos.

En lo que se refiere a las estructuras con un solo argumento interno, como se ha expuesto desde el capítulo 2, las características que definen en primera instancia la aparición del MDO en español son aquellas que no se constituyen de manera relacional. En este caso, la escala que determina en mayor medida la marca preposicional es la animacidad. Teniendo en cuenta este rasgo, los SN que mayor probabilidad tienen de aparecer marcados son aquellos con referente humano; el ámbito de los animados no humanos presenta mayor variación; y, por último, en los inanimados la marca preposicional es aún excepcional (a pesar de que se ha documentado su incipiente expansión en algunas variedades). Tras la animacidad, la escala que define la zona de marcado en español es la de definitud/especificidad. En lo que a esta escala respecta, actualmente se marcan en español todos los pronombres, nombres propios y SN definidos con función de objeto directo. Dentro del ámbito de los SN indefinidos aún existe variación, pues mientras los específicos siempre reciben MDO, no es este el caso de aquellos con una lectura no específica, con los que aún es posible la ausencia de marcado.

En un segundo plano, desempeñan su papel aquellos rasgos que se definen de forma relacional, es decir, afectación y agentividad. Estos factores no actúan

27 Lazard (2003) define la «zona de objeto» como aquella que delimita la noción de objeto y que incluye al objeto prototípico, pero también a todos aquellos actantes que presentan características en común con él, aunque no compartan todas las que lo definen. 
de una forma tan determinante como los primeros. En lo que a la afectación respecta, este mismo trabajo ha demostrado, no solo a nivel sincrónico, sino también diacrónico, la relevancia de este rasgo en lo que al MDO se refiere. No obstante, el efecto de la afectación se ha observado en contextos con SN indefinidos humanos, es decir, tan solo en aquellos SN lo suficientemente prominentes, desde el punto de vista de sus rasgos inherentes, como para permitir el uso de la marca (humanos), pero no tanto como para establecerla como obligatoria (indefinidos). En términos de Laca (2006), podría decirse que la afectación desempeña su papel en la zona de posibilidad que delimitan los factores inherentes al SN.

En lo que se refiere a la agentividad, su contribución en primera instancia la realiza en la localización del Actor o Proto-Agente. Una vez establecido este, se le asigna la función de sujeto, atendiendo al principio de selección argumental de Dowty, y las relaciones de prominencia respecto al grado de agentividad se establecen nuevamente entre los argumentos restantes, para destacar aquel objeto que posea mayor número de rasgos proto-agentivos; es decir, aunque los objetos no van a presentar nunca el rasgo de causante del evento -en términos de Dowty (1991)-, de control -según Primus (1999)-, o de instigador -atendiendo a la clasificación de Næss (2007)-, sí pueden presentar el resto de características y, por tanto, se puede establecer entre los distintos argumentos internos una relación de prominencia en términos de agentividad. Según este planteamiento, el efecto de la agentividad no sería posible demostrarlo en estructuras con un solo argumento interno; por ello será en las oraciones ditransitivas donde realmente adquiera mayor visibilidad. No obstante, donde la agentividad ha sido estudiada con mayor detalle, debido a la ausencia de solapamiento con el rasgo de la animacidad, ha sido en el ámbito de los objetos inanimados. Este es, precisamente, el contexto en el que el MDO presenta en español la función desambiguadora de una forma más evidente.

Existen en español una serie de verbos que, cuando aparecen acompañados por dos argumentos inanimados (uno interno y otro externo), siempre exigen la marca preposicional de su argumento interno, a pesar su falta de animacidad o, incluso, de su indefinitud. Entre estos verbos encontramos algunos como preceder, suceder, sustituir o remplazar, entre otros cuantos. El razonamiento que subyace en este caso al uso de la marca es el de la necesidad de distinguir el sujeto del objeto ante la expresión simultánea de dos argumentos similares en cuanto a sus (escasos) rasgos de agentividad. Así pues, teniendo en cuenta que el papel temático que establece en primera instancia la agentividad es el de Proto-agente/Actor y en este contexto no es evidente, partiendo del escaso grado de agentividad de ambos participantes, surge la necesidad de marcar el objeto para determinar el papel que desempeña cada participante (véase García García 2007; 2014; 2018 para un análisis más detallado). Más allá del orden oracional o 
la concordancia sujeto-verbo, pruebas asociadas a la función de sujeto, pero cuya información no siempre es capaz de resolver la ambigüedad, el español no posee ninguna marca morfológica para señalar el papel de Proto-agente; por lo tanto, la lengua recurre necesariamente al uso del MDO, que como se ha dicho, funciona en español como indicador de la condición de objeto y es en estos casos el único mecanismo del que se dispone para eliminar la ambigüedad.

Analizado el efecto de los distintos factores en oraciones con un solo argumento interno, se describe a continuación de qué manera se extiende el enfoque propuesto a aquellas con dos argumentos distintos del Actor/Proto-Agente. No obstante, antes de entrar propiamente en el efecto de los factores, es importante mencionar algunos datos acerca de las estructuras ditransitivas en español, qué las define y cuál ha sido su evolución histórica. Ortiz Ciscomani (2011, 54), en el estudio diacrónico de este tipo de estructuras que lleva a cabo, defiende que la construcción ditransitiva (o bitransitiva) de significado prototípico implica un evento de sentido causativo conceptualizado en términos de transmisión de fuerza. Esto significa que cada evento involucra individuos que actúan sobre individuos: un participante activo causa que una entidad que está bajo su dominio entre, al concluir el evento, al ámbito o dominio propio de otro participante, igualmente activo, pero en menor medida. La construcción ditransitiva es, por tanto, una estructura causal en la que las relaciones gramaticales (S) - OD - OI corresponden al orden de participación en una cadena causal de transmisión de energía (Croft 1991, 162).

En lo que se refiere a la marcación de los objetos en estas estructuras, Ortiz Ciscomani documenta dos tipos de esquemas de marcado a lo largo de la historia del español: uno en el que el objeto directo aparece sin marca y el objeto indirecto marcado; y otro en el que ambos objetos aparecen marcados. Al primero de ellos lo denomina esquema típico, por tratarse del más extendido a lo largo del tiempo (99\% (3027/3061)), mientras que al segundo de ellos se refiere como esquema atípico, por suponer tan solo el 1\% (34/3061) de la totalidad de casos estudiados. Los hipotéticos esquemas de marcado en los que el objeto indirecto apareciese sin marcar no se documentan en español, pues la marca preposicional ha sido obligatoria con el indirecto desde los orígenes de la lengua. El esquema de marcado típico se debe, principalmente, a que los objetos concurrentes en una estructura ditransitiva se caracterizan fundamentalmente por su asimetría léxica, sobre todo en cuanto a su animacidad. El objeto directo es típicamente inanimado, en tanto que el indirecto es típicamente humano. En lo que a la definitud respecta, ambos argumentos son sensibles a la definitud, pero, mientras que el objeto indirecto es generalmente definido, el directo muestra bastante flexibilidad respecto a este rasgo.

No obstante, además de la animacidad y la definitud, Ortiz Ciscomani apunta que el cambio que experimenta un objeto directo de una estructura ditransitiva 
es simplemente el derivado de la transferencia, es decir, un cambio de ubicación, por lo que el grado de afectación de un objeto directo en este tipo de estructuras no será nunca tan fuerte como el que puede experimentar un objeto directo en una estructura monotransitiva $(2011,111)$. Destaca, asimismo, que la afectación es una propiedad común tanto al objeto directo como al indirecto, aunque ambos quedan afectados de distinta manera. El objeto indirecto representa una entidad afectada indirectamente por el evento (valga la redundancia), con conciencia o actividad manifiesta en el hecho de «recibir» el objeto directo; es una «locación animada», destino final del evento, en tanto que el objeto directo es una entidad generalmente inanimada, concreta y manipulable. Así pues, el objeto indirecto es el punto de referencia, es decir, una entidad cognitivamente más saliente (o prominente) que el resto de las involucradas en el evento y a partir de la cual el emisor del enunciado establece contacto con el objeto directo (Ortiz Ciscomani 2011, 156).

En definitiva, lo que se observa en las estructuras ditransitivas que Ortiz Ciscomani cataloga como prototípicas es que el único objeto que aparece marcado es el que previsiblemente debería estarlo en lo que respecta a las relaciones de prominencia: el objeto indirecto. De los dos objetos, el indirecto presenta un mayor grado de prominencia desde el punto de vista de sus características intrínsecas, pues se caracteriza por ser animado (humano) y definido; y a nivel relacional, como hemos visto, es el que resulta más afectado, en el sentido de que constituye la meta final de la transferencia de fuerza; y, además, después del Proto-Agente/ Actor, es el que más rasgos proto-agentivos posee.

Ahora bien, es interesante observar qué es lo que ocurre cuando las estructuras se apartan de la «ditransitividad prototípica» y los objetos concurrentes en ellas son dos objetos animados o humanos; pues es precisamente en este contexto donde adquieren mayor relevancia los ya mencionados esquema típico y esquema atípico de marcación, en términos de Ortiz Ciscomani. Estas estructuras con dos argumentos animados, que tan solo suponen en torno a un 11\% (247/2269) del total de casos analizados, aparecen representadas mayoritariamente con el esquema de marcación típico, es decir, objeto directo sin marca y objeto indirecto marcado. Lo que esto significa es que, mientras que en las ditransitivas con un objeto animado y otro inanimado, se podía atribuir el hecho de que el objeto indirecto sea siempre el que aparece marcado al factor de la animacidad, en este caso vemos que lo más frecuente es que el objeto directo continúe apareciendo sin marca preposicional, porque el resto de factores que intervienen en el MDO y que definen las relaciones de prominencia siguen favoreciendo al objeto indirecto frente al directo. Este hecho es el que vendría a explicar la marcación obligatoria del objeto indirecto, pues, en el caso de concurrir dos argumentos, el indirecto se constituye como más prominente, bien a causa de las características intrínsecas 
del sintagma que desempeña dicha función y del resto de factores relacionales, o bien debido tan solo a la acción de estos últimos. Este es precisamente el funcionamiento que reflejan las lenguas de objeto primario/secundario, en las que el objeto primario se corresponde con el objeto directo de las estructuras monotransitivas o con el indirecto de las ditransitivas; mientras que el directo de las ditransitivas hace las veces de objeto secundario (Dryer 1986, 814).

Llegados a este punto, quedaría tan solo por explicar qué es lo que ocurre en ese pequeño número de estructuras ditransitivas (en torno al 1\% (34/3061)) en las que concurren dos objetos animados y que responden al patrón atípico de marcado, es decir, en las que ambos objetos aparecen marcados preposicionalmente. Los casos a los que me refiero son los representados en (144) y han sido analizados por diferentes autores (Campos 1999; Rodríguez-Mondoñedo 2007; Ortiz Ciscomani 2011; von Heusinger 2018).

(144) Estructuras ditransitivas con marcado «atípico»

a. Luis envió a su hijo al médico.

b. El profesor presentó a su mujer a sus alumnos.

Ortiz Ciscomani $(2011,161)$ defiende que la marca preposicional en estos casos provoca que ambos objetos se asemejen formalmente, producto de la cercanía o identidad de los valores que comparten (animacidad, definitud y rasgos de agentividad). Asume, además, que el objeto directo queda en estos casos menos afectado, al aparecer más individuado, y que la motivación del marcado ha de ser de orden predominantemente pragmático. En cuanto a estas dos afirmaciones, a pesar de que discrepo en el análisis que la autora mantiene para realizar la primera, creo que la intuición que subyace a la segunda es acertada.

En primer lugar, si el MDO se considera como un indicador de un alto grado de prominencia, lo esperable sería que el objeto directo en estos casos fuese más prominente que en aquellos casos en los que no aparece marcado. Por lo tanto, la afirmación de que en estos contextos queda menos afectado al presentar rasgos que implican mayor individuación, no tiene mucho sentido a la luz de enfoques como los de Mithun (1999) o Næss (2007), según los cuáles lo que ocurre es exactamente lo opuesto, a mayor grado de individuación, mayor probabilidad alcanza el objeto de quedar afectado.

Por otra parte, partiendo de que en estos casos el objeto directo supera en grado de prominencia al indirecto (pues de no ser así, no aparecería marcado), es factible el hecho de que dicho grado de prominencia tenga un alto componente pragmático, basado en la percepción del emisor o en la relevancia que adquiere un determinado participante en la realización de un evento concreto. La respuesta a por qué en el indirecto se mantiene la marca es sencilla, y es que esta no puede 
desaparecer; sin embargo, tal como señala Ortiz Ciscomani, el menor grado de prominencia del indirecto queda reflejado en la solución más frecuente a la ambigüedad causada por la doble marcación: la degradación argumental. Debido a la ambigüedad acerca el estatus de objeto que es más prominente, creada al concurrir ambos objetos marcados, este tipo de construcciones es sumamente raro en la lengua y lo más frecuente es que, para expresar el sentido en que el objeto directo es más prominente, se opte por construcciones oblicuas del tipo de las de (145).

(145) Estructuras equivalentes a las de doble objeto

a. Luis envió a su hijo a la consulta del médico.

(argumento > adjunto)

b. El profesor presentó a su mujer ante sus alumnos.

(argumento > adjunto)

Además, volviendo sobre los ejemplos de (144), son numerosos los autores que sostienen que el MDO ejerce un efecto de bloqueo ante la aparición del pronombre de dativo para duplicar el objeto indirecto, tal y como se aprecia en (146) (Campos 1999; Rodríguez-Mondoñedo 2007; Fábregas 2013).

(146) Duplicación de clítico dativo en estructuras ditransitivas

a. ??Luis le envió a su hijo al médico.

b. ??El profesor les presentó a su mujer a sus alumnos.

Este efecto estaría provocado por el hecho de que, como se desprende de la definición de prominencia, un elemento prominente es el que puede servir de anclaje estructural para otras estructuras o mecanismos gramaticales; así pues, la duplicación del objeto es, en principio, solo posible cuando el objeto indirecto es el elemento más prominente de los dos, como puede observarse en (147) (cf. Company Company 2001; 2003; 2006).

(147) Duplicación de clítico dativo en estructuras ditransitivas

a. Luis le envió su hijo al médico.

b. El profesor les presentó su mujer a sus alumnos.

A pesar de todo, como se ha señalado más arriba, estas estructuras con doble objeto marcado no acaban de resultar naturales del todo para muchos hablantes y el mecanismo más común suele ser, en caso de considerar el objeto directo como el más prominente, convertir el indirecto en una Meta o en algún otro tipo de adjunto. 


\subsection{Conclusiones}

La pregunta que ha motivado este capítulo buscaba una explicación lingüística a la influencia que la afectación ha demostrado sobre el MDO, junto al resto de factores que se presentaron en el capítulo 2. La teoría que se ha propuesto pasa por considerar el marcado preposicional como un elemento indicador de que un determinado argumento presenta una serie de rasgos que lo caracterizan como objeto prominente, en un sentido en el que el término objeto incluye tanto a objetos directos como indirectos.

Esta idea de que realmente el marcado preposicional es el mismo tanto en el objeto directo como en el indirecto, a pesar de que pueda dar lugar a funciones sintácticas diferentes, no surge de la nada, sino que son numerosos argumentos los que la respaldan. En primer lugar, la propuesta parte de mismo origen del MDO. La preposición $a$ en latín se constituye, antes que nada, como marca del caso dativo, y su posterior expansión a determinados acusativos se produce en contextos en los que semánticamente más próximos se encuentran ambos casos: aquellos objetos humanos, altamente definidos, con función de tópico y, en cierta manera, afectados por la acción del verbo.

El principal reto de este capítulo ha sido, de hecho, el de intentar explicar de qué manera se podía llegar a considerar esa afectación compartida por ambos objetos, a la que nos referimos, y la propuesta que se ha realizado pasa por considerar la afectación el producto de la transferencia de energía que implican los eventos. Así pues, un evento se concibe en términos de transferencia de energía, donde un Agente provoca la creación de una cadena causal de energía, partiendo de la acción designada por el verbo, a través de la cual quedan afectados todos aquellos participantes del evento distintos de aquel que lo ha iniciado. En estos términos, la afectación pasa a considerarse la propiedad que realmente define el carácter de objeto, pero de objeto en un sentido amplio, como señalábamos al principio.

En la percepción de la afectación, a su vez, influyen rasgos como la animacidad y la definitud, pues cuanto mayor sea el carácter humano y definido de un objeto, mayor será el grado de empatía -en palabras de Dahl/Fraurud (1996) y Dahl (2008) - y la capacidad para quedar afectado -según Mithun (1999) y Næss (2007)-. Adoptando este enfoque, el hecho de que el MDO se extendiese desde el dativo a ciertos acusativos cobra sentido a la luz de que a partir de ese momento la marca comienza a constituirse como señal de aquellos objetos prominentes en términos de animacidad y definitud, que además presentan un determinado carácter de objeto, en el sentido de que quedan afectados por la acción verbal. 
Para concluir esta investigación, en el siguiente capítulo se ha recogido las conclusiones e ideas más relevantes que se han obtenido a lo largo de la realización de este trabajo y, asimismo, se exponen tanto la relevancia de los resultados conseguidos a la luz del enfoque propuesto, como los caminos que este estudio deja abiertos en el campo de la investigación sobre el MDO, la transitividad y la conceptualización de los distintos fenómenos lingüísticos por medio de la noción de prominencia. 